\title{
NUCKSI Promotes Proliferation, Invasion and Migration of Non-Small Cell Lung Cancer by Upregulating CDKI Expression
}

This article was published in the following Dove Press journal: Cancer Management and Research

\author{
Shufen Zhao' \\ Baiyao Wang ${ }^{2}$ \\ Yanning $\mathrm{Ma}^{3}$ \\ Junjie Kuang' \\ Jiyun Liang ${ }^{3}$ \\ Yawei Yuan ${ }^{1,2}$ \\ 'Department of Radiation Oncology, \\ Nanfang Hospital, Southern Medical \\ University, Guangzhou City, Guangdong \\ Province 510515, People's Republic of \\ China; ${ }^{2}$ Department of Radiation \\ Oncology, Affiliated Cancer Hospital and \\ Institute of Guangzhou Medical \\ University, Guangzhou City, Guangdong \\ Province 510095, People's Republic of \\ China; ${ }^{3}$ Shunde Hospital, Southern \\ Medical University, Foshan City, \\ Guangdong Province 528308, People's \\ Republic of China
}

Background: Non-small cell lung cancer (NSCLC) is a predominant type of lung cancer with a high mortality rate.

Objective: The aim of this study is to investigate the roles of nuclear casein kinase and cyclin-dependent kinase substrate 1 (NUCKS1) in NSCLC and to identify the potential mechanisms.

Materials and Methods: The expression of NUCKS1 in several NSCLC cells was detected firstly. Then, NUCKS1 was overexpressed or silenced in both A549 and NCI-H460 cells, where cell proliferation, invasion and migration were, respectively, determined, using CCK8 , colony formation assay, transwell and wound healing assays. Cell cycle analysis was performed, and the expression-associated proteins were detected by Western blotting. Subsequently, NCI-H460 cells with NUCKS1 overexpression for the subsequent tumorbearing experiment. And the NUCKS1 expression in tumor tissues was measured by means of immunohistochemistry and Western blotting. Additionally, the STRING database predicted that Cyclin-Dependent Kinase 1 (CDK1) would bind to NUSK1, which was verified by the co-immunoprecipitation assay. Then, CDK1 was silenced by transfection with short hairpin RNA (shRNA)-CDK-1 or by exposure to CDK1 inhibitor p2767-00. And the biological characteristics of proliferation, invasion and migration were examined.

Results: Results indicated that NUCKS1 was overly expressed in NSCLC cells, and its overexpression promoted proliferation, invasion and migration of both A549 and NCI-H460 cells while NUCKS1 knockdown displayed the opposite effects. Moreover, the results of the xenograft experiments revealed that NUCKS1-upregulation promoted the tumor growth. Furthermore, the immunoprecipitation assay verified CDK1's interaction with NUCKS1, and CDK1 knockdown alleviates the impact of NUCKS1 overexpression on NSCLC cell proliferation, invasion and migration.

Conclusion: Taken together, these findings demonstrated that NUCKS1 promotes proliferation, invasion and migration of NSCLC by upregulating CDK1, providing a novel putative target for the clinical treatment of NSCLC.

Keywords: non-small cell lung cancer, NUCKS1, proliferation, migration, CDK1

\section{Introduction}

Lung cancer, a cancer that occurs in the respiratory system, is considered to be one of the most frequent malignancies, with a high mortality rate, as it leads to approximately 1.6 million tumor-related deaths annually in the world. ${ }^{1,2}$ Nonsmall cell lung cancer (NSCLC) is a predominant type of lung cancer that accounts
Nanfang Hospital, Southern Medical

University, 1838 Guangzhou Dadao

North, Guangzhou City, Guangdong

Province 5105I5, People's Republic of

China

Email yuanyawei33@I63.com
Cancer Management and Research 2020:12 I33|I-13323

| 33 | |

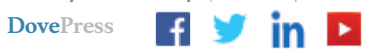

http://doi.org//0.2147/CMAR.S282/8| 
for over $80 \%$ of cases with a low 5-year survival rate. ${ }^{3,4}$ During the past few decades, despite the significant advances in the understanding of NSCLC pathogenesis, the 5-year survival rate of patients with NSCLC only marginally improved. 5,6 Poor prognosis in patients with NSCLC is associated with the lack of early diagnostic biomarkers and its great potential for invasion and metastasis. $^{7}$ Therefore, elucidating the detailed molecular mechanism underlying the progression of NSCLC and identifying novel therapeutic targets are urgently required for the treatment of NSCLC.

The nuclear casein kinase and cyclin-dependent kinase substrate 1 (NUCKS1) is a $27 \mathrm{kDa}$ highly phosphorylated nuclear protein that participates in DNA damage response. ${ }^{8}$ A growing body of literature has shown that NUCKS1 is overexpressed in multiple cancers and may therefore contribute to oncogenesis. ${ }^{9}$ For instance, when overexpressed in gastric cancer tissues, NUCKS1 could intensify gastric cancer aggressiveness by activating the PI3K/Akt/mTOR signaling pathway. ${ }^{10}$ NUCKS1 was identified as a potential oncogene in hepatocellular carcinoma patients, and it might be a valuable immunodiagnostic marker for the disease. ${ }^{11}$ NUCKS1 was reported to be highly expressed in cervical squamous cell carcinoma and perhaps related to tumor progression. ${ }^{9}$ Emerging evidence supports that NUCKS1 was found to be an inescapable element in lung cancer. $^{12}$ The STRING website (https://string-db.org/) predicts Cyclin-Dependent Kinase 1 (CDK1)' interaction with NUCKS1, as CDK1 is involved in the cell cycle progression and dysregulation and is widely associated with tumor development and progression in various types of cancers. ${ }^{13,14}$ In addition, CDK1 serves as a potential prognostic biomarker and target for lung cancer. ${ }^{15}$ However, the role of NUCKS1 in the progression of NSCLC and the effect of its regulating $\mathrm{CDK} 1$ remain unclear.

In this study, the expression of NUCKS1 in several NSCLC cell lines was determined firstly. Subsequently, the biological activity, the growth and metastasis of lung cancer cells were investigated in vitro and in vivo. The potential mechanisms underlying NUCKS1 functioning in NSCLC were explored. These data may provide a novel therapeutic target for the control of NSCLC progression.

\section{Materials and Methods}

\section{Cell Culture}

One normal human bronchial epithelioid cell line (BEAS2B) and several lung cancer cell lines (A549, NCI-H292,
NCI-H358 and NCI-H460) were all obtained from American Type Culture Collection (ATCC). Cells were grown in Dulbecco's Modified Eagle Medium (DMEM; Gibco, Thermo Fisher Scientific, USA) accompanied with $10 \%$ fetal bovine serum (FBS; Gibco) at $37^{\circ} \mathrm{C}$ in a humidified incubator with $5 \% \mathrm{CO}_{2}$.

\section{Cell Transfection}

Prior to cell transfection, cells were dispensed into a 6-well plate and cultured at $37^{\circ} \mathrm{C}$ until $80 \%$ confluence. Subsequently, NUCKS1-overexpressing plasmid (oeNUCKS1), the empty vector plasmid (oe-NC), short hairpin RNA (shRNA) targeted against NUCKS1 (shRNA-NUCKS1 -1 or shRNA-NUCKS1-2) and a scrambled shRNA as a negative control (shRNA-NC), shRNA-CDK1-1, shRNACDK1-2 and sh-NC were synthesized by Shanghai GenePharma co., ltd (Shanghai, China), which were transfected into A549 or NCI-H460 cells using Lipofectamine 3000 (Invitrogen, Carlsbad, CA, USA) in accordance with the manufacturer's guidelines. Forty-eight hours after the transfection, reverse transcription-quantitative polymerase chain reaction (RT-qPCR) assay was performed to evaluate the success of it.

\section{Cell Viability Assay}

Cell survival was detected by Cell Counting Kit-8 (CCK8; Shanghai Yi Sheng Biotechnology Co., Ltd.) assay in accordance with the manufacturer's protocol. In short, cells $\left(1 \times 10^{4}\right.$ cells/well) were planted in 96-well culture plates. Twenty four, 48 and $72 \mathrm{~h}$ after the transfection, $10 \mu \mathrm{L}$ CCK-8 solution was added to each well. The cells were incubated at $37^{\circ} \mathrm{C}$ for $1 \mathrm{~h}$, followed by the absorbance inspection at $450 \mathrm{~nm}$ wavelength with a microplate absorbance reader.

\section{Colony Formation Assay}

Cells were plated into $6-\mathrm{cm}$ dishes (1000 cells per well) and were then incubated for 14 days at $37^{\circ} \mathrm{C}$ until the colonies could be observed, after which cells were fixed with $4 \%$ paraformaldehyde and stained with $0.2 \%$ crystal violet.

\section{Cell Cycle Analysis}

The cell cycle distribution was examined using the Cell Cycle Analysis kit (Beyotime Institute of Biotechnology) in accordance with the manufacturer's guidelines. Transfected A549 and NCI-H460 cells were collected and centrifuged at $600 \mathrm{~g}$ for $5 \mathrm{~min}$ and the supernatant was removed. Cells were 
treated with 70\% cold ethanol and $100 \mu \mathrm{g} / \mathrm{mL}$ RNase (Nanjing KeyGen Biotech Co., Ltd.). After being stained with $30 \mu \mathrm{g} / \mathrm{mL}$ propidium iodide (Nanjing KeyGen Biotech Co., Ltd.) in the dark, the samples were analyzed by using a Gallios Flow Cytometer (Beckman Coulter, Inc.). All data were examined by FlowJo software (Tree Star, Inc.).

\section{Transwell Assay}

The invasion ability of A549 and NCI-H460 cells was detected using an 8 - $\mu \mathrm{m}$ pore insert coated with Matrigel (BD Biosciences). A total of $200 \mu \mathrm{L}$ serum-free medium containing cells was added to the upper chamber, while the bottom chamber was filled with a medium containing $10 \%$ FBS to stimulate invasion. After $48 \mathrm{~h}$ of incubation, cells invading the lower chamber were fixed by $4 \%$ paraformaldehyde and were then stained with $0.1 \%$ crystal violet. Images were captured using an inverted microscope (Olympus Corporation). Five visual fields were randomly selected and the number of cells passing through the micropore in each visual field was counted by Image J software (National Institutes of Health).

\section{Wound Healing Assay}

For the wound healing assay, A549 and NCI-H460 cells were seeded in a 6-well culture plate and were incubated at $37^{\circ} \mathrm{C}$ with $5 \% \mathrm{CO}_{2}$. When cells reached approximately $90 \%$ confluency, the wound was generated by scratching the surface of the cell monolayer using a sterilized $200-\mu \mathrm{L}$ pipette tip. Photographs were recorded at time 0 and at 24 $\mathrm{h}$ post cell scratch under an inverted microscope (Olympus Corporation). Image $\mathrm{J}$ software (National Institutes of Health) was utilized to calculate the area of each wound.

\section{Tumor Formation in Mice}

Male BALB/c nude mice (4 weeks old) were purchased from the Shanghai SLAC Animal Laboratory (Shanghai, China). All animals were housed in an environmentally controlled breeding room at a temperature of $20-25^{\circ} \mathrm{C}$ and 20-30\% humidity, through a $12 \mathrm{~h}$ light $/ 12 \mathrm{~h}$ dark cycle for 3 days before experiments. Animal experiments were performed in accordance with a protocol approved by the Animal Experiment Ethics Committee of the Southern Medical University. All related procedures conformed to the Animal Protection Act of China. And a total of $2 \times 10^{6}$ NCI-H460 cells were subcutaneously implanted afterwards into the right armpit of every male nude mice. Tumors were measured every 2 days with a handheld caliper.

\section{Immunohistochemistry Analysis}

The sections were deparaffinized and endogenous peroxidase activity was quenched with $10 \%$ normal goat serum (Wuhan Servicebio Technology Co., Ltd.) for $15 \mathrm{~min}$. Then, the tumor sections were incubated with the primary NUCKS1 antibody at $4^{\circ} \mathrm{C}$ overnight. After incubation with horseradish peroxidase-conjugated secondary antibody, the slides were stained with diaminobenzidine and counterstained with hematoxylin. An inverted microscope (Olympus Corporation) was used to obtain Microscopic images.

\section{Immunofluorescence Assay}

After fixation in $4 \%$ paraformaldehyde overnight at $4^{\circ} \mathrm{C}$, the tumor tissues were dehydrated, cleared and waxed. Paraffin-embedded posterior segments were sectioned into $5 \mu \mathrm{m}$ slices, which were baked at $60^{\circ} \mathrm{C}$ for $2 \mathrm{~h}$. After being deparaffinized in xylene, the segments were rehydrated in graded ethanol, followed by a wash with water. The sections were then blocked using bovine serum albumin (BSA; Sigma-Aldrich; Merck KGaA). After being probed with primary antibodies recognizing $\mathrm{Ki} 67$ (Abcam) at $4^{\circ} \mathrm{C}$ overnight, the sections were incubated with the secondary antibody (Abcam). Nuclei were stained with DAPI solution (Roche Diagnostics) in the dark and Ki67 was stained in green. Images were taken under an Olympus microscope (Tokyo, Japan).

\section{Co-Immunoprecipitation (IP) Assay}

For co-immunoprecipitation assays, cells were lysed in Lysis Buffer for IP (Beyotime Institute of Biotechnology). Lysates were incubated with indicated antibodies plus Protein $\mathrm{A} / \mathrm{G}$ beads (Santa Cruz Biotechnology, Inc.). After the beads were washed, immunoprecipitates were analyzed by Western blotting.

\section{RT-qPCR}

Total RNA from cells prepared by using TRIzol ${ }^{\circledR}$ reagent (Invitrogen, Carlsbad, CA, USA). Subsequently, according to the manufacturer's instruction, the complementary DNA (cDNA) was synthesized from $2 \mu \mathrm{g}$ of total RNA with a Reverse Transcription kit (Takara, Japan). Quantitative PCR was conducted using an ABI 7500 system (Applied Biosystems; Thermo Fisher Scientific, Inc.). All primers used in the present study were synthesized by Sangon Biotech. The relative expression of target genes was 

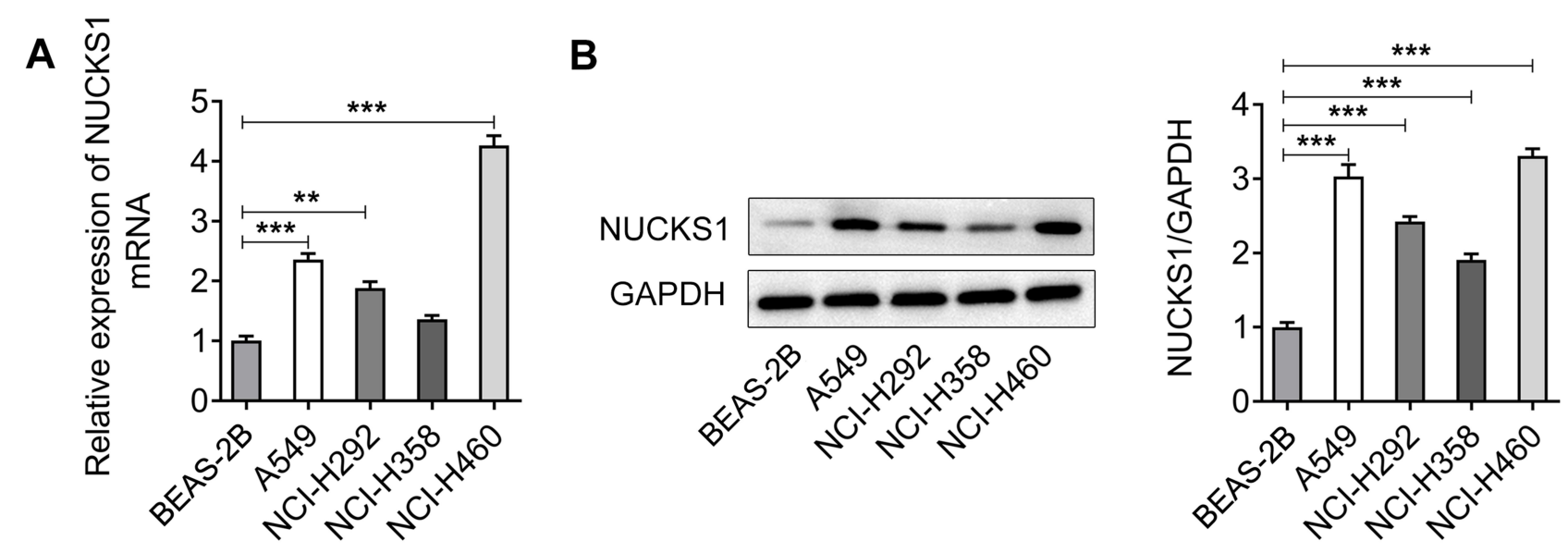

A549
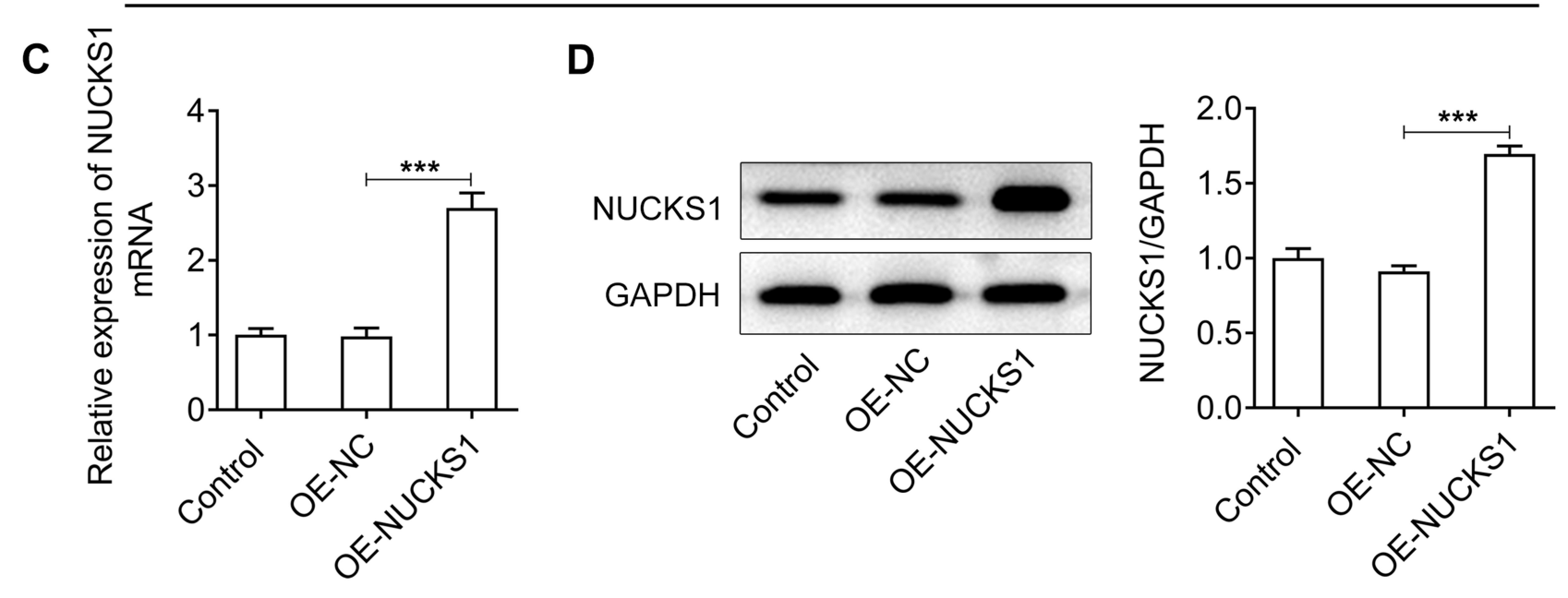

$\mathrm{NCl}-\mathrm{H} 460$
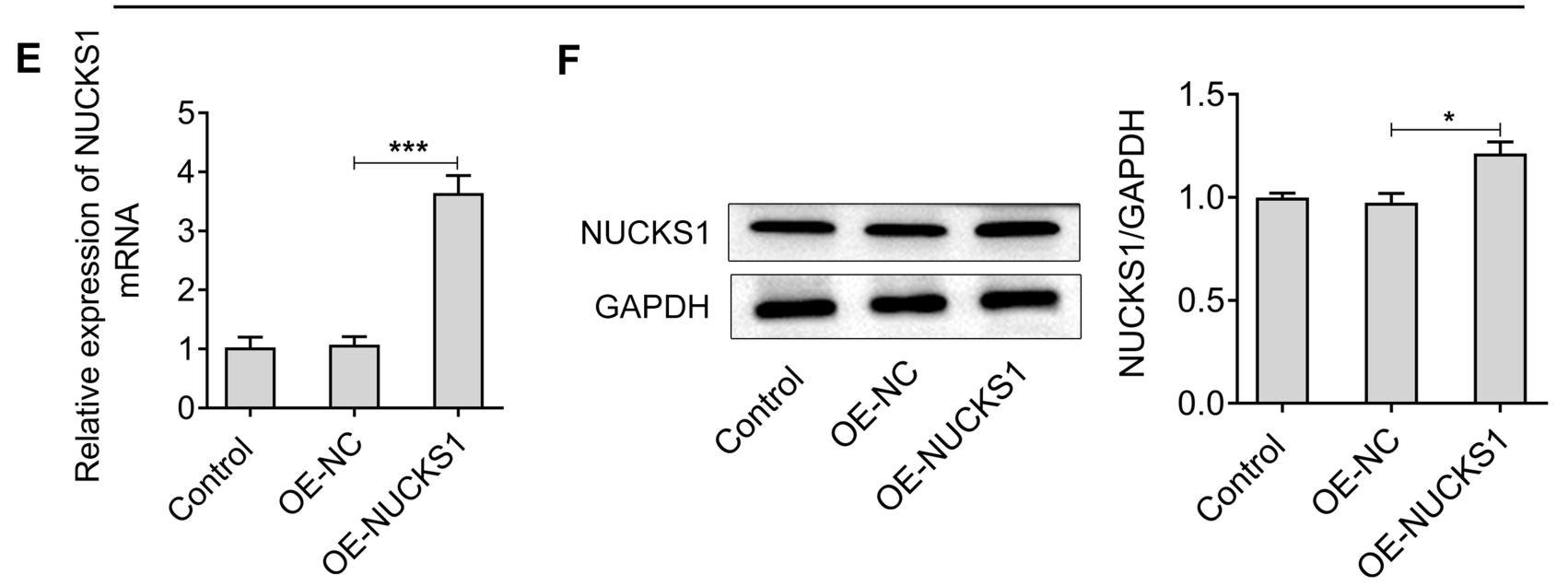

Figure I NUCKSI expression was significantly upregulated in NSCLC cells. The expression of NUCKSI in several NSCLC cells (A549, NCl- $\mathrm{H} 292, \mathrm{NCl}-\mathrm{H} 358$ and $\mathrm{NCl}-$ $\mathrm{H} 460)$ and one normal human bronchial epithelioid cell line (BEAS-2B) was detected using (A, B) RT-qPCR and Western blot analysis. $* * P<0.0 \mathrm{I}$ and $* * * \mathrm{P}<0.00 \mathrm{I}$. The levels of NUCKSI in A549 cells were determined using (C, D) Western blot analysis and RT-qPCR after transfection with OE-NUCKSI. ****P<0.00I. The expression of NUCKSI in $\mathrm{NCl}-\mathrm{H} 460$ cells was evaluated by $(\mathbf{E}, \mathbf{F})$ Western blot analysis and RT-qPCR after transfection with OE-NUCKSI. $* \mathrm{P}<0.05$ and $* * * \mathrm{P}<0.00 \mathrm{I}$. 
represented as the fold-induction using the $2^{-\Delta \Delta C q}$ method. ${ }^{16}$ GAPDH was regarded as an internal reference.

\section{Western Blot Analysis}

Total protein was extracted using ProteinExt Mammalian Total Protein Extraction Kit (TransGen) and quantified with BCA protein quantitative kit (BioVision, Milpitas, California). Then, protein was separated by SDS-PAGE and transferred onto PVDF membranes (Thermo Fisher Scientific). Membranes were incubated with the corresponding primary antibody at $4^{\circ} \mathrm{C}$ overnight, and then washed and incubated with the corresponding secondary antibody at room temperature for $1 \mathrm{~h}$. After then, the membranes were washed and the blots were exposed with Hanbio Super-sensitive ECL Iuminescence Reagent (HANBIO, Shanghai, China)

Total protein was extracted using ProteinExt Mammalian Total Protein Extraction Kit (TransGen) and quantified with BCA protein quantitative Kit (BioVision, Milpitas, California). Then, protein was separated by SDS-PAGE and transferred onto PVDF membranes (Thermo Fisher
Scientific). Membranes were incubated with the corresponding primary antibody at $4^{\circ} \mathrm{C}$ overnight, and then washed and incubated with the corresponding secondary antibody at room temperature for $1 \mathrm{~h}$. After then, the membranes were washed and the blots were exposed with Hanbio Super-sensitive ECL Iuminescence Reagent (HANBIO, Shanghai, China)

Radioimmunoprecipitation assay (RIPA) lysis buffer (Beyotime, Shanghai, China) was used to extract total protein from cells or tissues, which was then quantified with BCA protein quantitative Kit (Beyotime, Shanghai, China). Equivalent protein was separated on $10 \%$ SDSPAGE, followed by it being transferred onto PVDF membranes (Thermo Fisher Scientific). Nonspecific binding sites were blocked with $5 \%$ skimmed milk and subsequently incubated with the corresponding primary antibody. These blots were further incubated afterwards, with HRP-conjugated secondary antibody. Protein bands were visualized using Odyssey Infrared Imaging Scanner (LICOR Biosciences) and were analyzed using Image J software (National Institutes of Health). GAPDH was employed as an internal control.
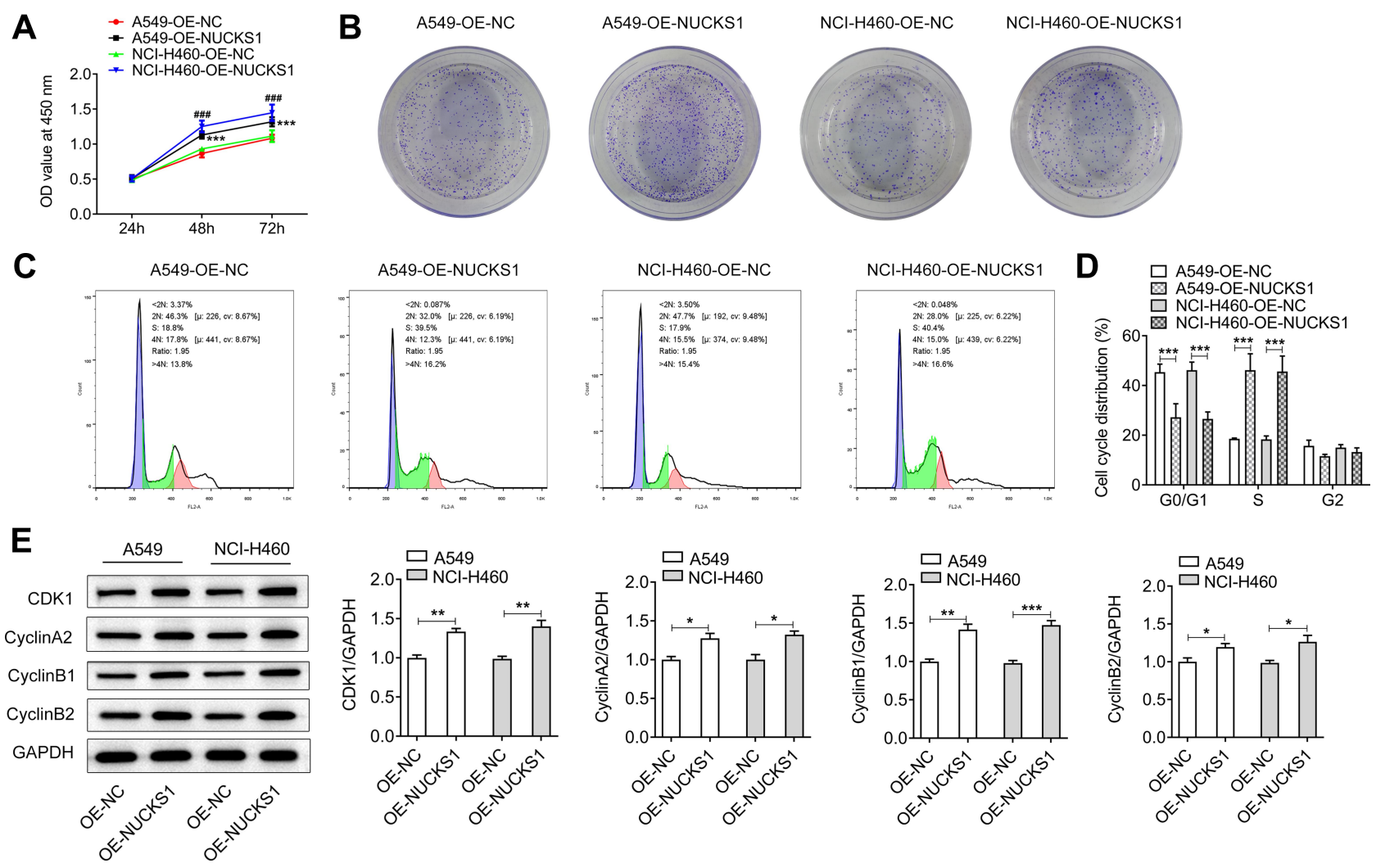

Figure 2 Overexpression of NUCKSI promotes the proliferation and inhibits cell cycle arrest of A549 and NCl-H460 cells. (A) Cell viability was tested using a CCK-8 kit. **** $\mathrm{P}<0.001$ vs $\mathrm{A} 549-\mathrm{Oe}-\mathrm{NC}$; ${ }^{\# \#+0.001} \mathrm{Ps} \mathrm{NCl}-\mathrm{H} 460-\mathrm{Oe}-\mathrm{NC}$. (B) Cell proliferation was assessed using colony formation assay. (C and $\mathbf{D}$ ) Cell cycle distribution was detected using flow cytometer. (E) The expression of cell cycle-related proteins was measured using Western blot analysis. $* \mathrm{P}<0.05, * * \mathrm{P}<0.0 \mathrm{I}$ and $* * * \mathrm{P}<0.00 \mathrm{I}$. 


\section{Statistical Analysis}

Three biological replicates were included in each experiment. All data were expressed as the mean \pm standard deviation. Statistical analysis was performed with GraphPad Prism 8 (GraphPad Software, Inc.). Student's $t$-test was applied to the comparison between the two groups. Analysis of variance (ANOVA) was used with Tukey's post hoc test to examine the statistical significance of the differences among multiple independent groups. $\mathrm{P}<0.05$ was considered to indicate a statistically significant difference.

\section{Results}

\section{NUCKSI Expression Was Significantly Upregulated in NSCLC Cells}

Firstly, the expression of NUCKS1 in several NSCLC cell lines (A549, NCI-H292, NCI-H358 and NCI-H460) was, respectively, detected by RT-qPCR and Western blotting. As shown in Figure 1A and B, the level of NUCKS1 significantly increased in these cell lines compared with the BEAS-2B cells, especially in A549 and NCI-H460 cells, which were selected for performing the following experiments.

\section{NUCKSI Overexpression Accelerates the Proliferation, Invasion and Migration of $\mathrm{A} 549$ and $\mathrm{NCl}-\mathrm{H} 460$ Cells}

To study the effects of NUCKS1 on the progression of NSCLC, NUCKS1 was overexpressed by transfection with NUCKS1-overexpressing plasmid. Results obtained from Figure 1C-F presented the notable upregulation of NUCKS1 expression after transfection in A549 and NCI-H460 cells. Cell viability was examined afterwards using a CCK-8 kit. As displayed in Figure 2A, it was observed that the viability of A549 and NCI-H460 cells was markedly enhanced in the NUCKS1 overexpression group, compared to that in the overexpression empty vector group. Additionally, as what is observed from Figure 2B, NUCKS1-upregulation significantly
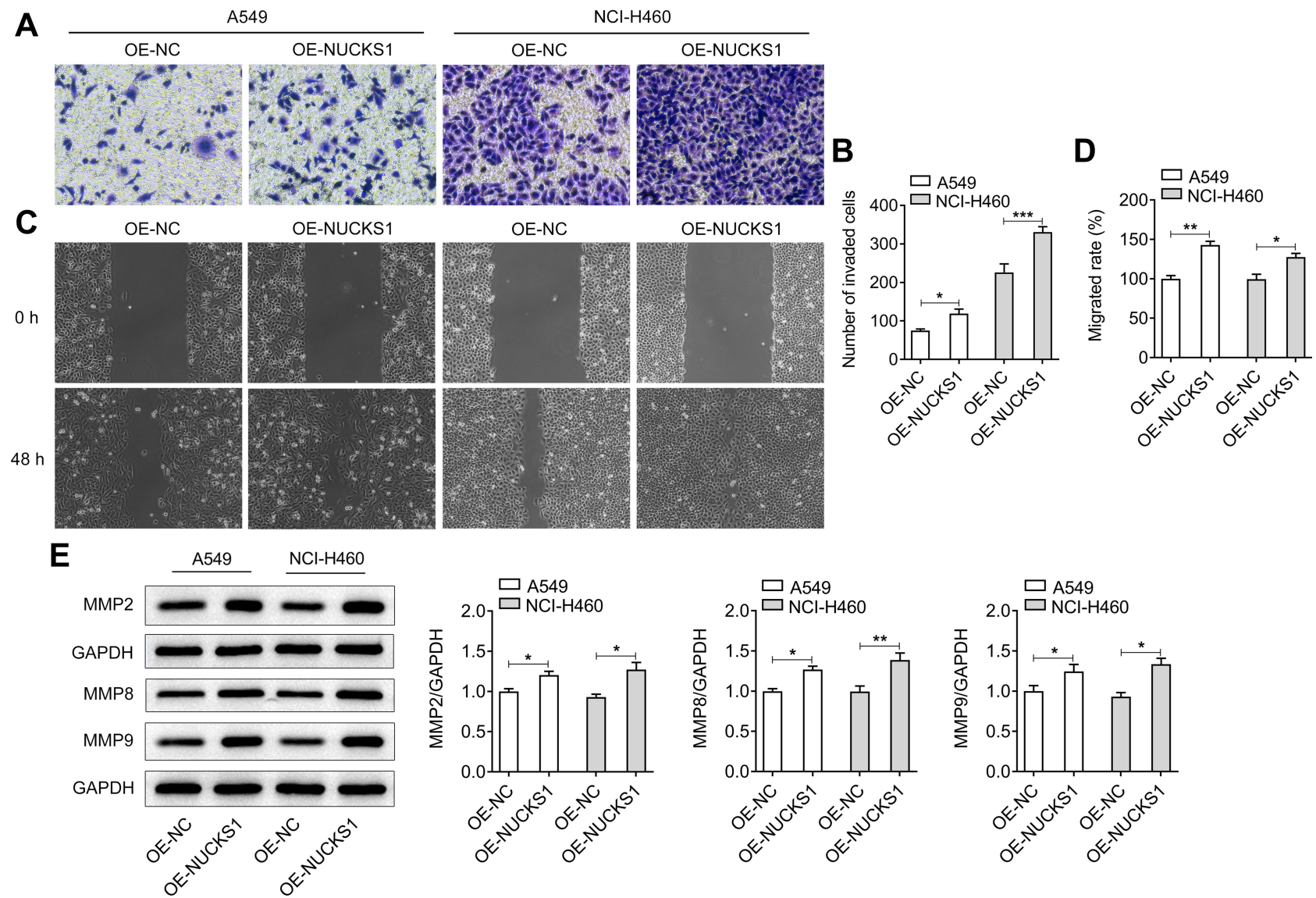

Figure 3 Overexpression of NUCKSI accelerates the invasion and migration of A549 and $\mathrm{NCl}-\mathrm{H} 460$ cells. (A) The invasive ability of A549 and NCl-H460 cells was determined using a Transwell assay. (B) Relative number of invaded cells. (C) Migratory activity of cells was detected using a scratch wound-healing assay. (D) Relative migratory rate was calculated. (E) Western blot analysis was used to evaluate the expressions of migration-related proteins. $* \mathrm{P}<0.05$, $* * \mathrm{P}<0.0 \mathrm{I}$ and $* * * \mathrm{P}<0.00 \mathrm{I}$. 
enhanced the ability of cell proliferation. Moreover, overexpression of NUCKS1 exhibited a decrease in the G0/G1 phase and an increase in the $\mathrm{S}$ phase compared with the corresponding OE-NC group in both A549 and NCI-H460 cells (Figure $2 \mathrm{C}$ and $\mathrm{D})$. Concurrently, the upregulated expression of cell cycle-related proteins, CDK1, cyclin A2, cyclin B1 and cyclin B2 also indicated the inhibitory effect of NUCKS1 in cell cycle arrest (Figure 2E). Subsequently, transwell and wound healing assays were employed to evaluate the effects of NUCKS1 overexpression on invasion and migration of NSCLC cells.
As exhibited in Figure 3A and B, NUCKS1-upregulation remarkably accelerated the invasive ability of A549 and NCIH460 cells in contrast to the OE-NC group. Correspondingly, the wound healing assay showed a similar result with that of the transwell assay (Figure 3C and D). Furthermore, it was noticed that the expression of migration-related proteins MMP2, MMP8 and MMP9 was greatly upregulated in the NUCKS1-upregulation group (Figure 3E). These results implicate that overexpression of NUCKS1 accelerates the proliferation, invasion and migration of A549 and NCI-H460 cells.
A

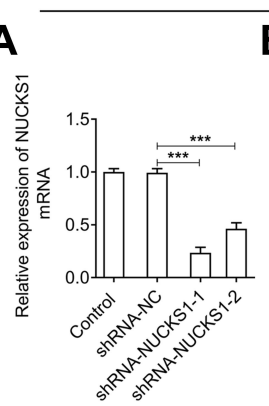

E

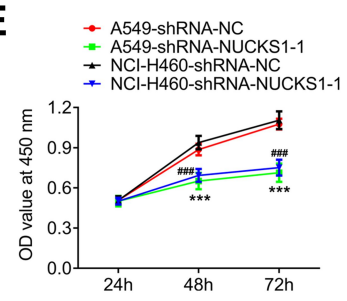

A549

\section{B}

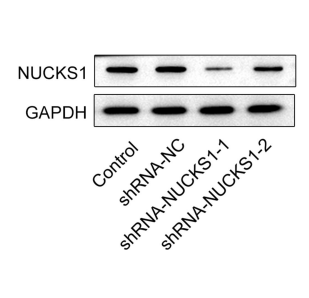

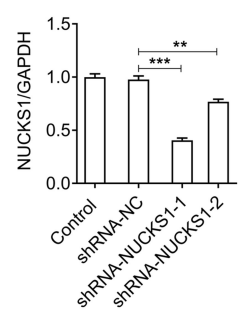

C

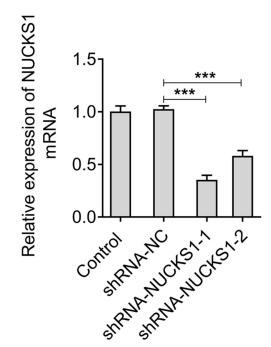

D

\section{$\mathbf{F}$}
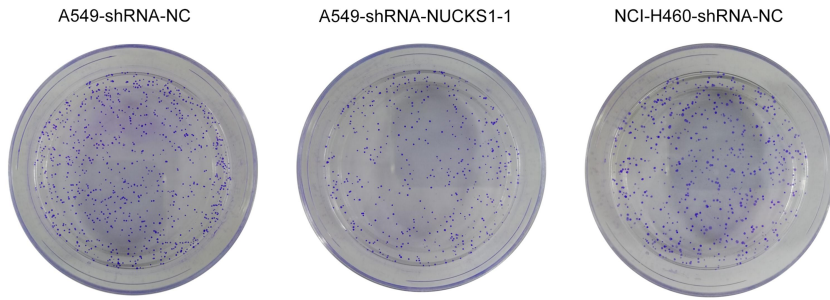

NCI-H460-ShRNA-NUCKS1-1

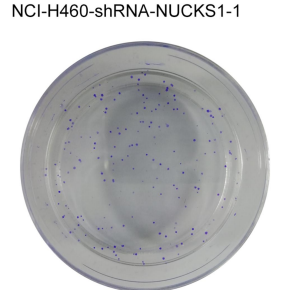

G
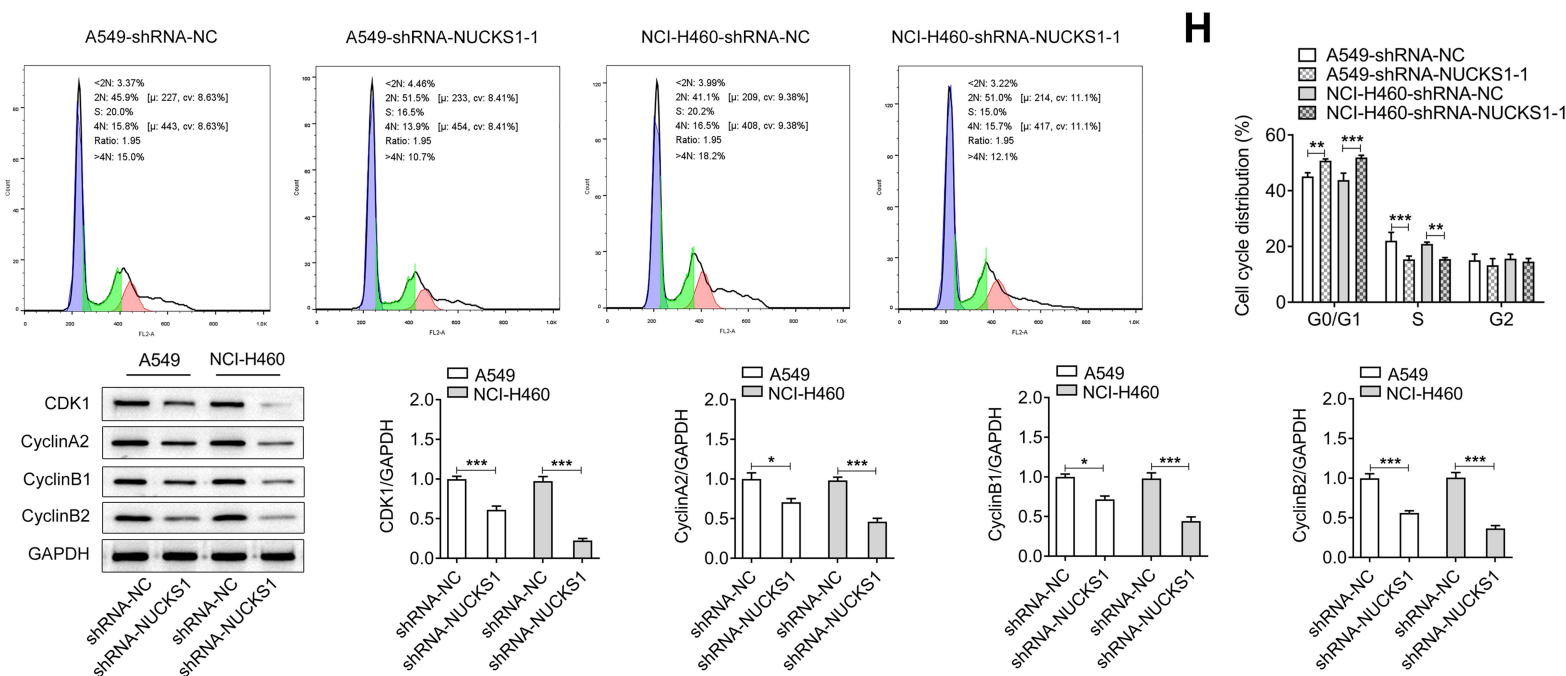

I
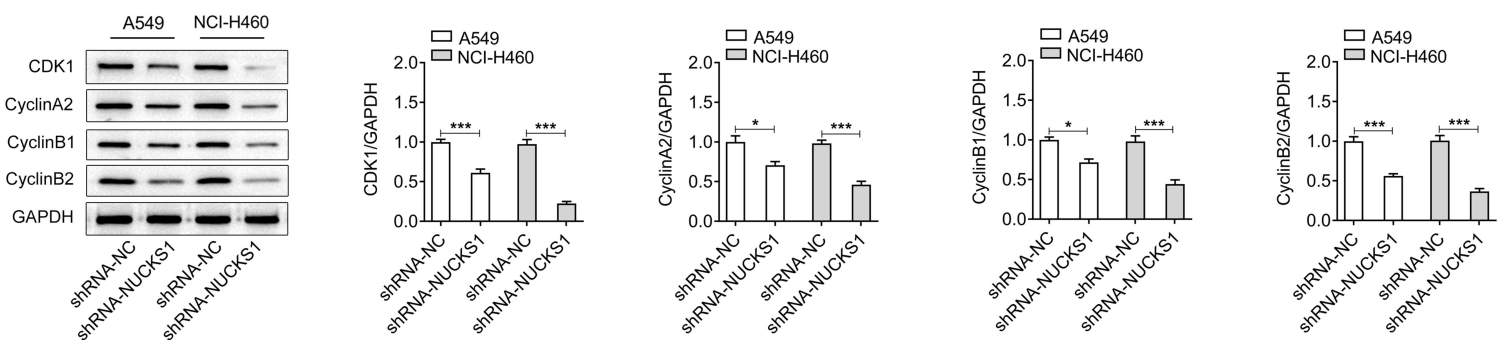

Figure 4 NUCKSI silencing attenuates the proliferation and promotes cell cycle arrest of $\mathrm{A} 549$ and $\mathrm{NCl}-\mathrm{H} 460$ cells. The expression of NUCKSI in A549 cells was tested using (A, B) Western blot analysis and RT-qPCR after transfection. NUCKSI level in NCl-H460 cells was detected using (C, D) Western blot analysis and RT-qPCR. $* * \mathrm{P}<0.0 \mathrm{I}$ and $* * * \mathrm{P}<0.00 \mathrm{I}$. (E) Cell viability was measured using a CCK-8 kit. ${ }^{* * *} \mathrm{P}<0.00 \mathrm{I}$ vs A549-shRNA-NC; ${ }^{\# \# P<0.00 I}$ vs NCl-H460-shRNA-NC. (F) Colony formation assay was employed to determine the proliferation of $\mathrm{A} 549$ and $\mathrm{NCl}-\mathrm{H} 460$ cells. ( $\mathbf{G}$ and $\mathbf{~ H ) ~ C e l l ~ c y c l e ~ d i s t r i b u t i o n ~ w a s ~ d e t e c t e d ~ u s i n g ~ f l o w ~ c y t o m e t e r . ~ ( I ) ~ E x p r e s s i o n ~ o f ~ c e l l ~}$ cycle-related proteins was measured using Western blot analysis. $* \mathrm{P}<0.05, * * \mathrm{P}<0.0 \mathrm{I}$ and $* * * \mathrm{P}<0.00 \mathrm{I}$. 


\section{NUCKSI Silencing Attenuates the} Proliferation, Invasion and Migration of A549 and NCl-H460 Cells

Subsequently, NUCKS1 was silenced to investigate the effect of NUCKS1 silencing on the cellular function. As displayed in Figure 4A and B, NUCKS1 protein and mRNA expression levels were notably reduced after transfection with shRNANUCKS1 in A549 cells, and the same results were found in the NCI-H460 cells (Figure 4C and D). Therefore, shRNANUCKS1-1 was chosen for conducting further experiments on the effect of lower expression of NUCKS1. It was found that NUCKS1-knockdown conspicuously suppressed the cell viability (Figure 4E) and proliferation (Figure 4F). Results in Figure $4 \mathrm{G}$ and $\mathrm{H}$ displayed the drastic promotion in the $\mathrm{G} 0 / \mathrm{G} 1$ phase and decline in the S phase after NUCKS1-1 silencing in A549 and NCI-H460 cells, suggesting a cell cycle arrest. Meanwhile, A549 and NCI-H460 cells' transfection with shRNA-NUCKS1-1 presented a significantly decreased expression of $\mathrm{CDK} 1$, cyclin $\mathrm{A} 2$, cyclin $\mathrm{B} 1$ and cyclin $\mathrm{B} 2$ (Figure 4I). Moreover, as what is observed from Figure 5A$\mathrm{D}$, the abilities of invasion and migration of A549 and NCIH460 cells were largely reduced following NUCKS1downregulation. And the expression of MMP2, MMP8 and MMP9 exhibited the same changing trend with invasion and migration in these two NSCLC cell lines (Figure 5E). Collectively, these data provide evidence that NUCKS1knockdown abrogates the proliferation, invasion and migration of A549 and NCI-H460 cells.

\section{Overexpression of NUCKSI Promotes the Growth of Lung Cancer Cells in vivo} The effect of NUCKS1 on the growth of lung cancer cells in vivo was explored afterwards in this study. After the establishment of xenograft models in mice, we performed 15 days of monitoring. The weight and tumor volume were found to be gradually increased in the OE-NUCKS1 group compared
A
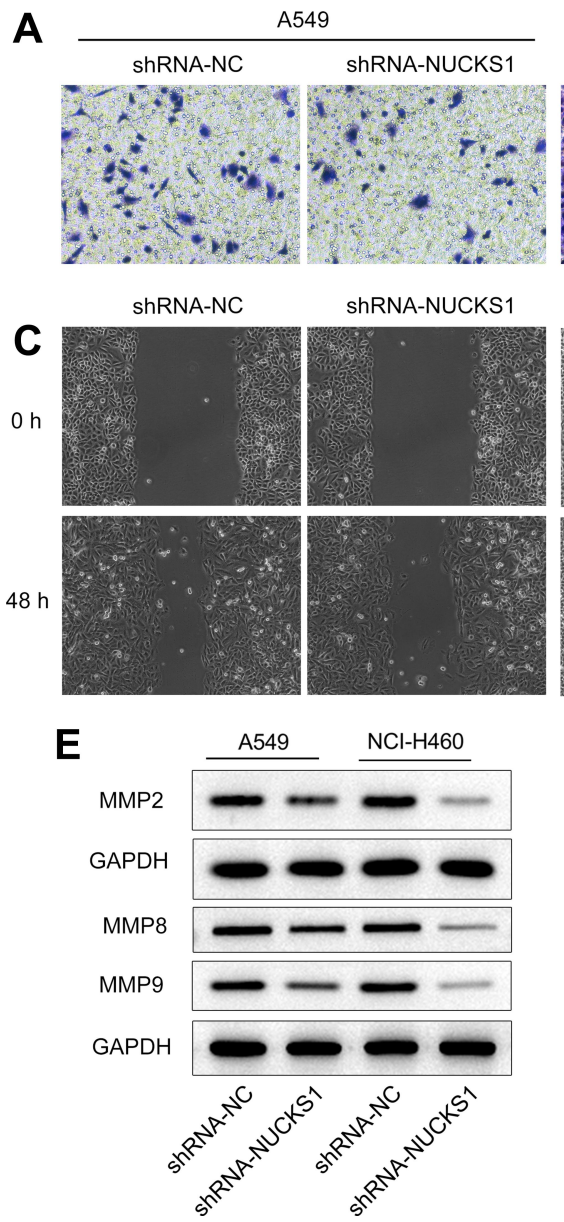
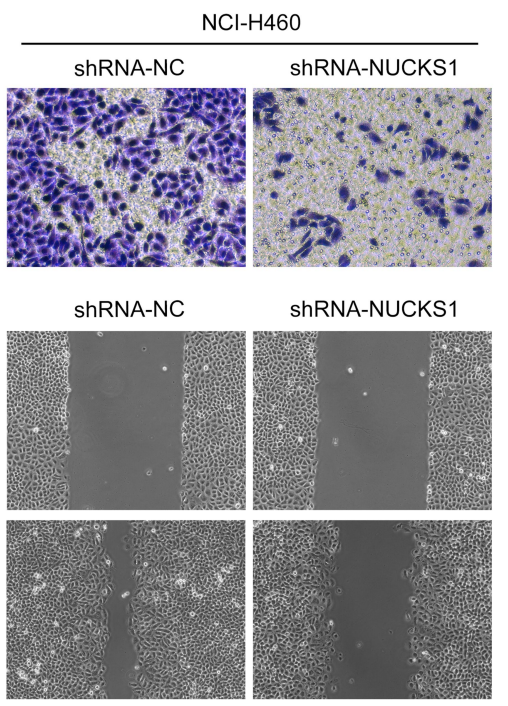

B

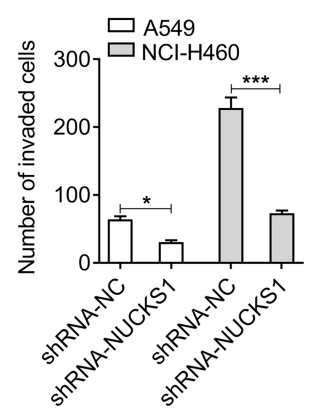

D

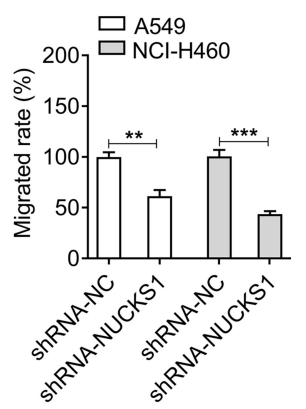

Figure 5 NUCKSI silencing suppresses the invasion and migration of A549 and NCl-H460 cells. (A and B) Cell invasion of A549 and NCl-H460 cells was evaluated using a Transwell assay. (C and D) Migratory activity of cells was detected using a scratch wound-healing assay. (E) The expressions of migration-related proteins was assessed by Western blot analysis. $* \mathrm{P}<0.05, * * \mathrm{P}<0.01$ and $* * * \mathrm{P}<0.001$. 
with the OE-NC group (Figure 6A-D). Furthermore, the expression of NUCKS1 in tumor tissues of OE-NUCKS1 group was notably upregulated in contrast to the OE-NC group (Figure 6E and F). Additionally, it was observed that proliferation-related gene Ki67 expression was markedly elevated in the tumor tissues when NCI-H460 cells were implanted into the mice with NUCKS1 overexpression (Figure 6G). These observations reveal that NUCKS1upregulation promotes the growth of lung cancer cells in vivo.

\section{CDKI-Knockdown Reverses the Impact of NUCKSI-Upregulation on Proliferation, Invasion and Migration of NSCLC Cells}

To further study the regulatory mechanisms of NUCKS1 in NSCLC, the STRING website was employed to predict the potential genes' interaction with NUCKS1. It was found that CDK1 can interact with NUCKS1 (Figure 7A), which was confirmed by co-IP-assay (Figure 7B). Then, CDK1 was silenced by transfection with shRNA-CDK1, and shRNACDK1-1 was used to carry out the following experiments (Figure 7C and D). Results of CCK-8 (Figure 7E) and colony formation (Figure 7F) assays exhibited that CDK1knockdown alleviated the viability and proliferation of NCIH460 cells relative to the OE-NUCKS1+shRNA-NC group. And CDK1 inhibitor p2767-00 presented the same results with shRNA-CDK1. Moreover, CDK1 silencing and p276700 dramatically enhanced the number of cells in the G0/G1 phase and reduced that of in the $\mathrm{S}$ phase (Figure $7 \mathrm{G}$ and $\mathrm{H}$ ). As expected, the upregulated expression of CDK1, cyclin A2, cyclin B1 and cyclin B2 was reversed by CDK1 silencing or p2767-00 treatment in NCI-H460 cells with NUCKS1 overexpression (Figure 7I). Subsequently, as observed from Figure 8A-D, CDK1 silencing or p2767-00 intervention noticeably inhibited the invasive and migratory abilities of NCI-H460 cells. Correspondingly, the expression of MMP2, MMP8 and MMP9 displayed a similar result with
A

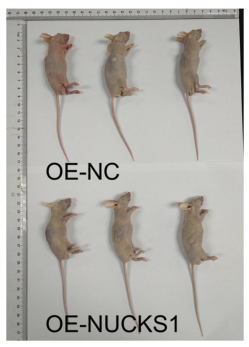

E

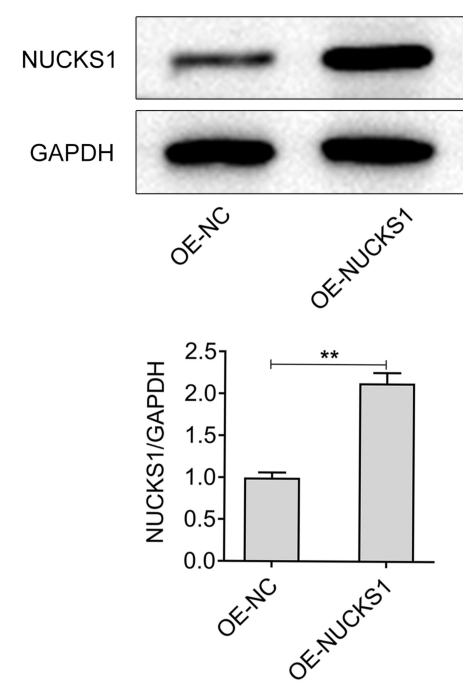

C

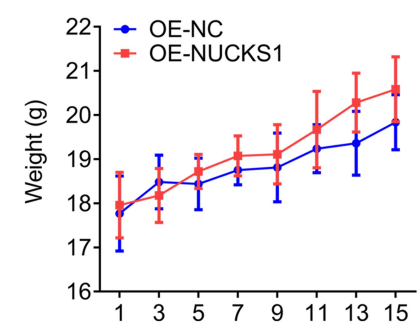

OE-NC

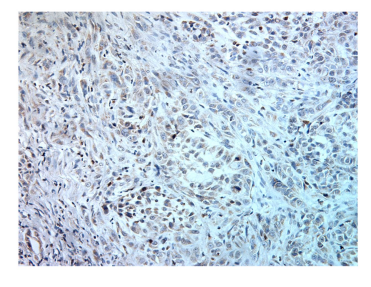

OE-NC

G

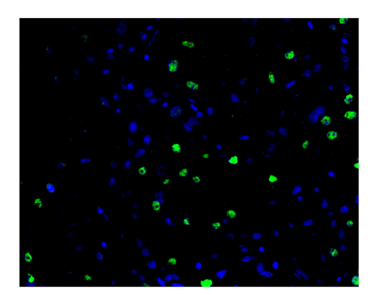

D

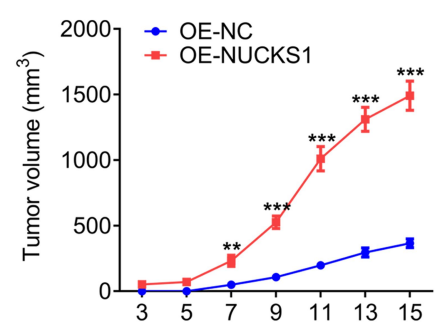

OE-NUCKS1

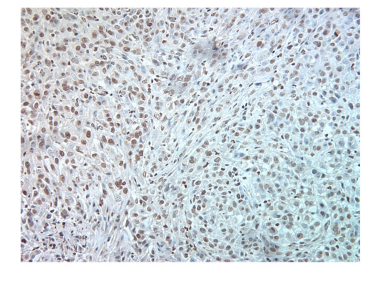

OE-NUCKS1

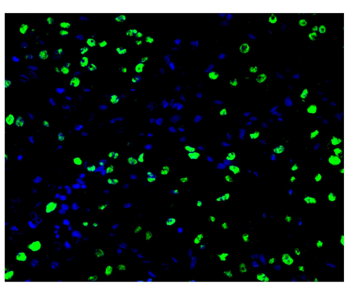

Figure 6 Overexpression of NUCKSI promotes the growth of lung cancer cells in vivo. (A and B) A total of $2 \times 10^{6} \mathrm{NCl}-\mathrm{H} 460$ cells were subcutaneously implanted into the right armpit of every male nude mice. The images of tumors were obtained at day 15 of inoculation. (C) The weight and (D) tumor volume were calculated every two days. $* * \mathrm{P}<0.01$ and $* * * \mathrm{P}<0.00 \mathrm{I}$ vs $\mathrm{OE}-\mathrm{NC}$. The expression of NUCKSI in tumor tissues was detected using (E) Western blot analysis and (F) Immunohistochemistry analysis. $* * \mathrm{P}<0.01$. (G) The expression level of Ki67 was measured using Immunofluorescence assay. 


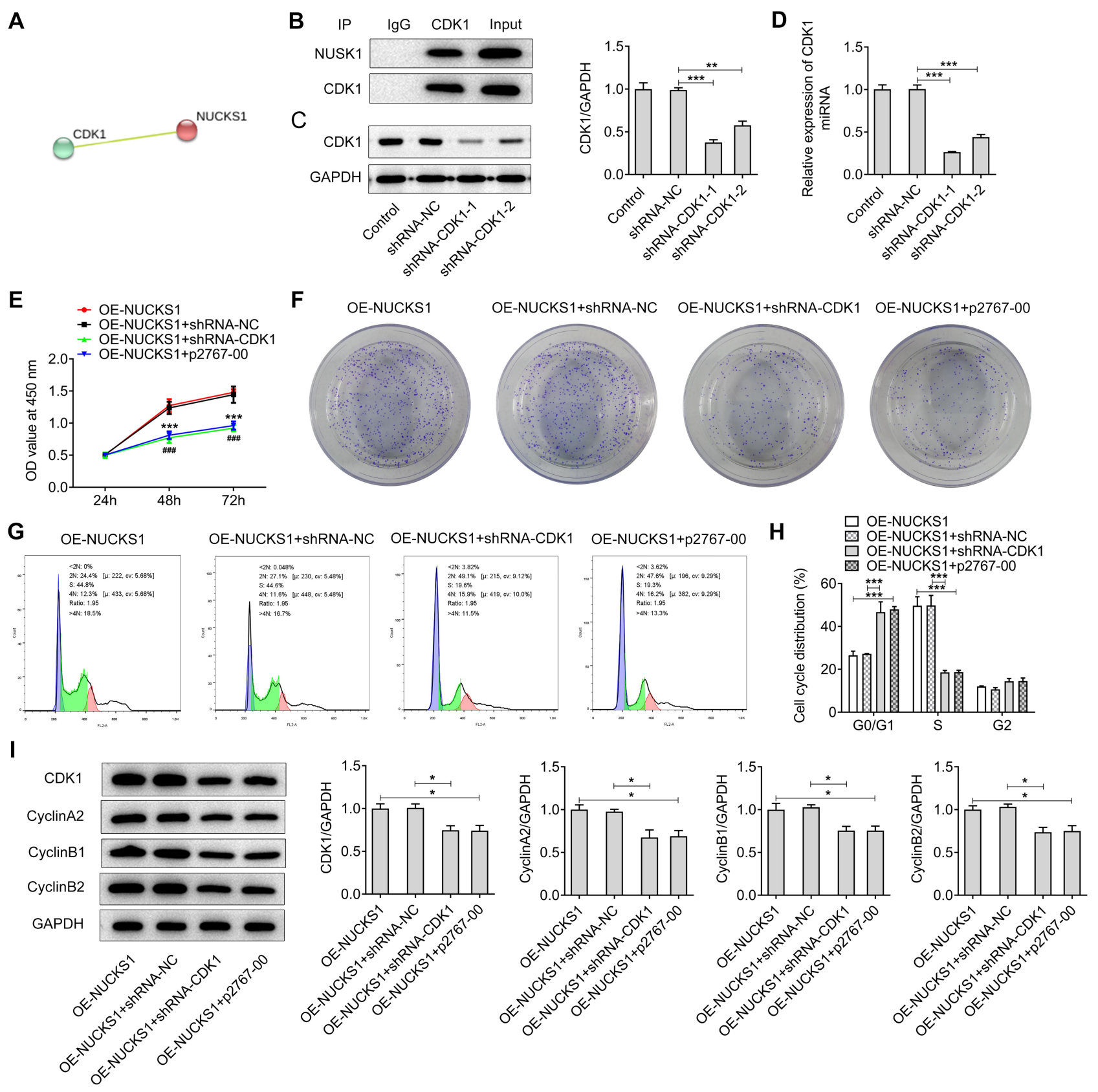

Figure 7 CDKI silencing reverses the impact of NUCKSI-upregulation on proliferation and cell cycle arrest in NCI-H460 cells. (A) The STRING website predicted CDKI's interaction with NUCKSI. (B) The combination between CDKI and NUCKSI was verified by co-immunoprecipitation assay. The expression of CDKI was measured using (C) Western blot analysis and (D) RT-qPCR after transfection with shRNA-CDKI. ${ }^{*} * \mathrm{P}<0.0 \mathrm{I}$ and $* * * \mathrm{P}<0.00 \mathrm{I}$. (E) Cell viability was tested using a CCK-8 assay. $* * * \mathrm{P}<0.00 \mathrm{I}$ vs OE-NUCKSI; ${ }^{\#} \mathrm{P}<0.001$ vs OE-NUCKSI+shRNA-CDKI. (F) Cell proliferation was determined using colony formation assay. (G and $\left.\mathbf{H}\right)$ Cell cycle distribution was detected using flow cytometer. (I) Expression of cell cycle-related proteins was measured using Western blot analysis. $* \mathrm{P}<0.05$ and $* * * P<0.00 \mathrm{I}$.

that of invasion and migration (Figure 8E). To sum up, these data provide evidence that CDK1-knockdown restores the impact of NUCKS1-upregulation on proliferation, invasion and migration of NSCLC cells.

\section{Discussion}

NSCLC accounts for a large proportion of cancer-related deaths. ${ }^{17}$ Despite the significant advances in the diagnostic and therapeutic techniques of lung cancer in recent decades, treatment results are far from satisfactory. Therefore, there exists an urgent demand for developing effective and safe therapies that target the aggressive progression and metastasis of NSCLC. This study is the first to reveal that NUCKS1 is highly expressed in multiple NSCLC cell lines. On the cellular level, NUCKS1 critically controls the proliferation, invasion and migration behavior of A549 

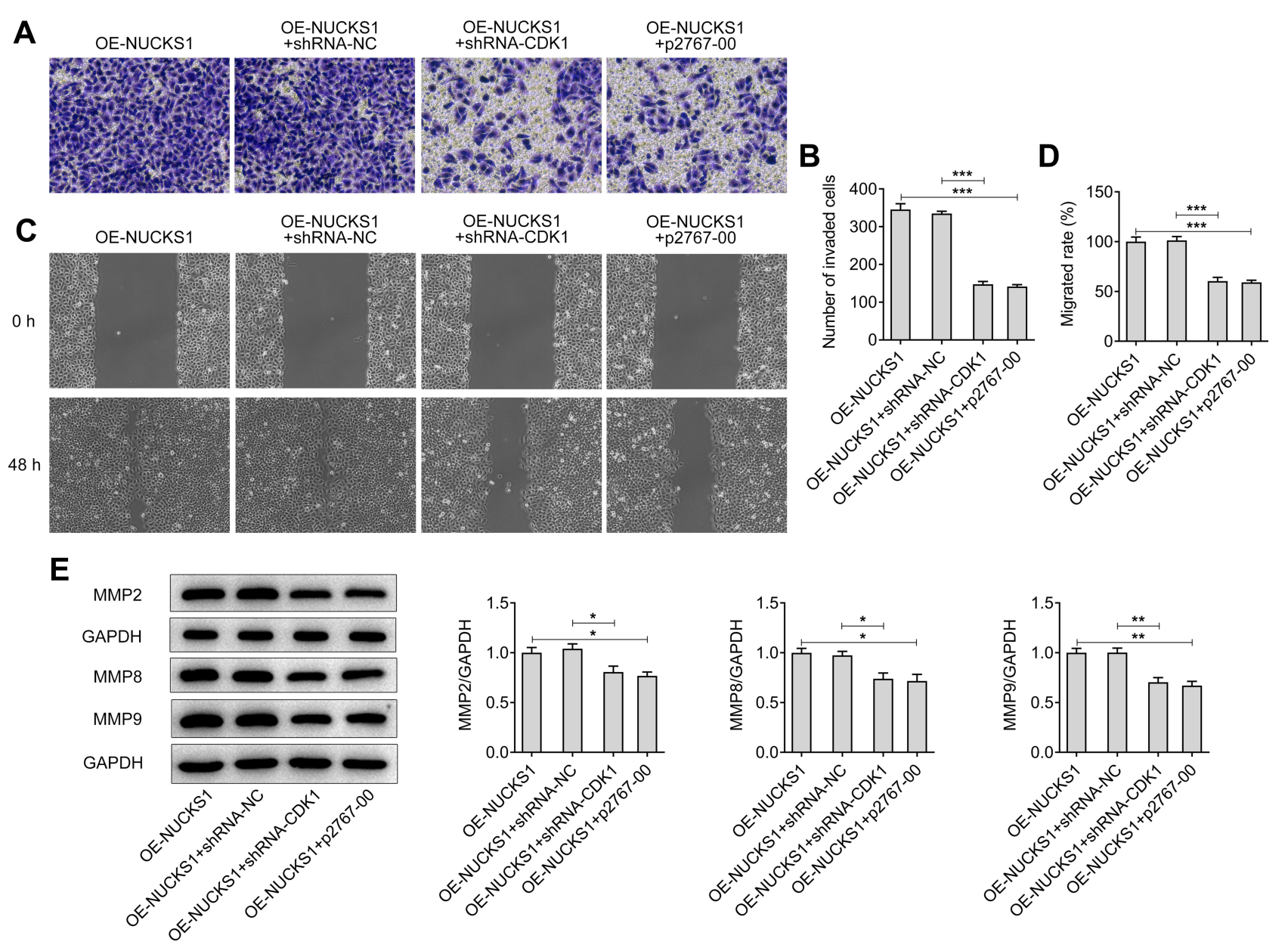

Figure $8 \mathrm{CDKI}$ silencing restores the inhibitory effects of NUCKSI overexpression on invasion and migration of $\mathrm{NCl}-\mathrm{H} 460$ cells. $(\mathbf{A}$ and $\mathbf{B})$ Cell invasion of $\mathrm{NCl}-\mathrm{H} 460$ cells was evaluated using a Transwell assay. (C and D) Migratory activity of cells was measured using a scratch wound-healing assay. (E) The expression of migration-related proteins was evaluated using Western blot analysis. ${ }^{*} \mathrm{P}<0.05$, $* * \mathrm{P}<0.0 \mathrm{I}$ and ${ }^{*} * \mathrm{P}<0.00 \mathrm{I}$.

and NCI-H460 cells, which is mediated through the regulation of CDK1 expression. Correspondingly, NUCKS1upregulation notably promotes tumor growth in vivo. These findings suggest that NUCKS1 is potentially a novel putative therapeutic target for the clinical treatment of NSCLC.

NUCKS1, a member of the high migration protein family, is located on chromosome 1q32.1 with a molecular weight of $27 \mathrm{kDa}^{18}$ A growing body of literature has shown that NUCKS1 exists extensively in multiple human tissues and participates in the occurrence and development of tumors. ${ }^{19,20}$ An increasing number of studies have revealed that NUCKS1 expression is markedly upregulated in a variety of tumor tissues, suggesting that NUCKS1 might contribute to oncogenesis. ${ }^{9,21}$ NUCKS1 was reported to be highly expressed in cervical squamous cell carcinoma and may be related to tumor progression. ${ }^{9}$ Kikuchi et al demonstrated that NUCKS1 expression level in colorectal cancer tissues and cells was greatly elevated, which was associated with significantly worse overall survival and relapse-free survival. ${ }^{22}$

Additionally, NUCKS1 was identified as a potential oncogene in hepatocellular carcinoma patients, and it might be a valuable immunodiagnostic marker for the disease. ${ }^{11}$ Importantly, NUCKS1 expression was found significantly upregulated in lung cancer. ${ }^{12}$ However, its precise role in the development of NSCLC remains unknown. The current study indicated that the expression level of NUCKS1 was prominently upregulated in several NSCLC cell lines, especially in A549 and NCI-H460 cells. Overexpression of NUCKS1 accelerated the proliferation, invasion and migration of A549 and NCI-H460 cells, while NUCKS1 silencing inhibited the above-mentioned cellular functions. Correspondingly, NUCKS1-upregulation notably promoted the growth of lung cancer cells in vivo, suggesting that NUCKS1 plays an indispensable role in the progression of NSCLC. 
To further study the regulatory mechanisms of NUCKS1 in NSCLC, the STRING website was employed to predict the potential genes' interaction with NUCKS1. It was found that CDK1 had the tendency to interact with NUCKS1, which was then confirmed by co-IP-assay in this study. CDK1 is involved in the cell cycle progression and dysregulation, and CDK1 serves as a potential prognostic biomarker and target for lung cancer. ${ }^{23}$ Previous studies reported that NUCKS1 appears to be important for cell cycle progression, and NUCKS1 is a substrate for CDK1. ${ }^{24,25}$ The normal growth and development of cells require the organic cooperation and orderly regulation of cell cycle family members. ${ }^{26}$ Cell cycle progression of eukaryotic is tightly regulated by complexes consisting of cyclins and CDKs, in which the complex of CDK1 and cyclin $\mathrm{B} 1$ is a key regulator of the cell cycle transition. ${ }^{27,28}$ Moreover, cyclin B2, a crucial member of the cell cycle family regulatory network, is reported to suppress damaged cells entering the mitotic phase. And the abnormal expression of cyclin B2 is related to the cell cycle regulation disorder, also triggering cell malignant transformation. ${ }^{29}$ This study revealed that NUCKS1 overexpression upregulated the expression of CDK1, cyclin A2, cyclin B1 and cyclin B2 in both A549 and NCIH460 cells. Following transfection with CDK1 or treatment with CDK1 inhibitor p2767-00, the impact of NUCKS1 overexpression on proliferation, invasion and migration of NSCLC cells was remarkably reversed.

\section{Conclusion}

Taken together, this study offers convincing evidence for the first time of the NUCKS1 being overly expressed in NSCLC cell lines. More importantly, it is identified that CDK1 can interact with NUCKS1, and NUCKS1 promotes proliferation, invasion and migration of NSCLC cells by upregulating CDK1 expression, which presents a novel promising target for the clinical diagnosis and the therapeutic interventions of NSCLC. However, the lack of the studies of verification about the clinical value of NUCKS1 in clinical tissue samples and the effect of NUCKS1 gene silencing on tumor formation in animals are limitations of the present research and therefore, a comprehensive analysis is required in the future.

\section{Data Sharing Statement}

The datasets used and/or analyzed during this study were accessed via the corresponding authors on reasonable request.

\section{Ethics Approval and Consent to Participate}

Animal experiments were performed in accordance with a protocol approved by the Animal Experiment Ethics Committee of the Southern Medical University.

\section{Disclosure}

The authors declare that they have no competing interests.

\section{References}

1. Hao H, Zhou Z, Li S, et al. Shell feature: a new radiomics descriptor for predicting distant failure after radiotherapy in non-small cell lung cancer and cervix cancer. Phys Med Biol. 2018;63(9):095007. doi:10.1088/1361-6560/aabb5e

2. Reck M, Rabe KF, Longo DL. Precision Diagnosis and Treatment for Advanced Non-Small-Cell Lung Cancer. N Engl J Med. 2017;377 (9):849-861. doi:10.1056/NEJMra1703413

3. Tian H, Zhou C, Yang J, Li J, Gong Z. Long and short noncoding RNAs in lung cancer precision medicine: opportunities and challenges. Tumour Biol. 2017;39(4):1010428317697578. doi: $10.1177 / 1010428317697578$

4. Tian Y, Zhang N, Chen S, Ma Y, Liu Y. The long non-coding RNA LSINCT5 promotes malignancy in non-small cell lung cancer by stabilizing HMGA2. Cell Cycle. 2018;17(10):1188-1198. doi:10.1080/15384101.2018.1467675

5. Chen Z, Fillmore CM, Hammerman PS, Kim CF, Wong -K-K. Nonsmall-cell lung cancers: a heterogeneous set of diseases. Nat Rev Cancer. 2014;14(8):535-546. doi:10.1038/nrc3775

6. Yang F, Yan Y, Yang Y, et al. MiR-210 in exosomes derived from CAFs promotes non-small cell lung cancer migration and invasion through PTEN/PI3K/AKT pathway. Cell Signal. 2020;73:109675. doi:10.1016/j.cellsig.2020.109675

7. Tang X-D, Zhang -D-D, Jia L, Ji W, Zhao Y-S. IncRNA AFAP1-AS1 Promotes Migration and Invasion of Non-Small Cell Lung Cancer via Up-Regulating IRF7 and the RIG-I-Like Receptor Signaling Pathway. Cell Physiol Biochem. 2018;50(1):179-195. doi:10.1159/ 000493967

8. Huang P, Cai Y, Zhao B, Cui L. Roles of NUCKS1 in diseases: susceptibility, potential biomarker, and regulatory mechanisms. Biomed Res Int. 2018;2018:7969068. doi:10.1155/2018/7969068

9. Gu L, Xia B, Zhong L, et al. NUCKS1 overexpression is a novel biomarker for recurrence-free survival in cervical squamous cell carcinoma. Tumour Biol. 2014;35(8):7831-7836. doi:10.1007/ s13277-014-2035-5

10. Huang Y-K, Kang W-M, Ma Z-Q, Liu Y-Q, Zhou L, Yu J-C. NUCKS1 promotes gastric cancer cell aggressiveness by upregulating IGF-1R and subsequently activating the PI3K/Akt/mTOR signaling pathway. Carcinogenesis. 2019;40(2):370-379. doi:10.1093/ carcin/bgy142

11. Cheong JY, Kim YB, Woo JH, et al. Identification of NUCKS1 as a putative oncogene and immunodiagnostic marker of hepatocellular carcinoma. Gene. 2016;584(1):47-53. doi:10.1016/j.gene.2016. 03.006

12. El-aarag SA, Mahmoud A, Hashem MH, Abd Elkader H, Hemeida AE, ElHefnawi M. In silico identification of potential key regulatory factors in smoking-induced lung cancer. BMC Med Genomics. 2017;10(1):11. doi:10.1186/s12920-017-0284-Z

13. Wang B, Hua P, Zhao B, Li J, Circular ZY. RNA circDLGAP4 is involved in lung cancer development through modulating microRNA-143/CDK1 axis. Cell Cycle. 2020;19(16):2007-2017. doi:10.1080/15384101.2020.1786649 
14. Liu Y, Li L, Wang XY, Wang P, Wang ZX. LncRNA TONSL-AS1 regulates miR-490-3p/CDK1 to affect ovarian epithelial carcinoma cell proliferation. J Ovarian Res. 2020;13(1):6. doi:10.1186/s13048020-00657-0

15. Li MY, He FY, Zhang ZC, Xiang ZF, Hu DF. CDK1 serves as a potential prognostic biomarker and target for lung cancer. J Int Med Res. 2020;48(2):12.

16. Livak KJ, Schmittgen TD. Analysis of Relative Gene Expression Data Using Real-Time Quantitative PCR and the 2- $\Delta \Delta \mathrm{CT}$ Method. Methods. 2001;25(4):402-408. doi:10.1006/meth.2001.1262

17. Zhao Y, Ye X, Chen R, et al. Sirtuin 7 promotes non-small cell lung cancer progression by facilitating G1/S phase and epithelial-mesenchymal transition and activating AKT and ERK1/2 signaling. Oncol Rep. 2020;44(3):959-972. doi:10.3892/or.2020.7672

18. Zhu K, Zhang Z, Zhang H, Wang Z, Wang F. RETRACTED ARTICLE: miR-142-3p targeting NUCKS1 inhibits proliferation and invasion of pancreatic cancer cells. Artif Cells Nanomed Biotechnol. 2020;48(1):415-424. doi:10.1080/ 21691401.2019.1652629

19. Drosos Y, Kouloukoussa M, Ostvold AC, et al. NUCKS overexpression in breast cancer. Cancer Cell Int. 2009;9(1):19. doi:10.1186/ 1475-2867-9-19

20. Yuan XH, Zhang MH, Ao JX, Zhen Z, Gao XJ, Li M. NUCKS1 is a novel regulator of milk synthesis in and proliferation of mammary epithelial cells via the mTOR signaling pathway. J Cell Physiol. 2019;234(9):15825-15835. doi:10.1002/jcp.28240

21. Schaner ME, Ross DT, Ciaravino G, et al. Gene expression patterns in ovarian carcinomas. Mol Biol Cell. 2003;14(11):4376-4386. doi:10.1091/mbc.e03-05-0279
22. Kikuchi A, Ishikawa T, Mogushi K, et al. Identification of NUCKS1 as a colorectal cancer prognostic marker through integrated expression and copy number analysis. Int $J$ Cancer. 2013;132 (10):2295-2302. doi:10.1002/ijc.27911

23. Zhang L, Peng R, Sun Y, Wang J, Chong XY, Zhang Z. Identification of key genes in non-small cell lung cancer by bioinformatics analysis. Peerj. 2019;7:14. doi:10.7717/peerj.8215

24. Ostvold AC, Norum JH, Mathiesen S, Wanvik B, Sefland I, Grundt K. Molecular cloning of a mammalian nuclear phosphoprotein NUCKS, which serves as a substrate for Cdk1 in vivo. Eur J Biochem. 2001;268 (8):2430-2440. doi:10.1046/j.1432-1327.2001.02120.x

25. Shen H, Wang L, Ge X, et al. MicroRNA-137 inhibits tumor growth and sensitizes chemosensitivity to paclitaxel and cisplatin in lung cancer. Oncotarget. 2016;7(15):20728-20742. doi:10.18632/oncotarget.8011

26. Ballew O, Lacefield LS. The DNA damage checkpoint and the spindle position checkpoint: guardians of meiotic commitment. Curr Genet. 2019;65(5):1135-1140. doi:10.1007/s00294-019-00981-z

27. Grana X, Reddy EP. Cell cycle control in mammalian cells: role of cyclins, cyclin dependent kinases (CDKs), growth suppressor genes and cyclin-dependent kinase inhibitors (CKIs).. Oncogene. 1995;11 (2):211-219.

28. Harper JW, Adams PD. Cyclin-dependent kinases. Chem Rev. 2001;101(8):2511-2526. doi:10.1021/cr0001030

29. Wang X, Zhang H, Jiao K, et al. Effect of miR-205 on proliferation and migration of thyroid cancer cells by targeting CCNB2 and the mechanism.. Oncol Lett. 2020;19(3):2568-2574. doi:10.3892/ ol.2020.11275
Cancer Management and Research

\section{Publish your work in this journal}

Cancer Management and Research is an international, peer-reviewed open access journal focusing on cancer research and the optimal use of preventative and integrated treatment interventions to achieve improved outcomes, enhanced survival and quality of life for the cancer patient.

\section{Dovepress}

The manuscript management system is completely online and includes a very quick and fair peer-review system, which is all easy to use. Visit http://www.dovepress.com/testimonials.php to read real quotes from published authors. 